\title{
Regulatory domain or CpG site variation in SLC12A5, encoding the chloride transporter KCC2, in human autism and schizophrenia
}

\author{
Nancy D. Merner ${ }^{1,2}$, Madison R. Chandler ${ }^{1}$, Cynthia Bourassa ${ }^{2}$, Bo Liang ${ }^{3}$, \\ Arjun R. Khanna ${ }^{4}$, Patrick Dion ${ }^{2}$, Guy A. Rouleau ${ }^{2 *}$ and Kristopher T. Kahle ${ }^{4,5 * \dagger}$

\begin{abstract}
Harrison School of Pharmacy, Department of Drug Discovery and Development, Auburn University, Auburn, AL, USA, ${ }^{2}$ Department of Neurology and Neurosurgery, Montreal Neurological Hospital and Institute, McGill University, Montréal, QC, Canada, ${ }^{3}$ Department of Biological Chemistry and Molecular Pharmacology (BCMP), Harvard Medical School, Boston, MA, USA, ${ }^{4}$ Department of Neurosurgery, Boston Children's Hospital and Harvard Medical School, Boston, MA, USA, ${ }^{5}$ Manton
\end{abstract} \\ Center for Orphan Disease Research, Boston Children's Hospital, Boston, MA, USA
}

OPEN ACCESS

Edited by: Ludovic MARTIN,

Université de Paris V, France

Reviewed by:

Melanie A Woodin,

University of Toronto, Canada

Wen-Jun Gao,

Drexel University College of Medicine,

USA

*Correspondence:

Guy A. Rouleau,

Department of Neurology and

Neurosurgery, Montreal Neurological

Hospital and Institute, Montréal,

QC, Canada

guy.rouleau@mcgill.ca;

Kristopher T. Kahle,

Department of Neurosurgery, Boston

Children's Hospital, Harvard Medical

School, 1309 Enders Research

Building, 320 Longwood Avenue,

Boston, MA 02115, USA

kkahle@enders.tch.harvard.edu

${ }^{\dagger}$ Present address:

Kristopher T. Kahle,

Department of Neurosurgery and

Pediatrics, Yale School of Medicine,

Yale Program on Neurogenetics,

New Haven, CT, USA

Received: 12 July 2015

Accepted: 16 September 2015

Published: 12 October 2015

Citation:

Merner ND, Chandler MR, Bourassa C, Liang B, Khanna AR, Dion P, Rouleau GA and Kahle KT (2015) Regulatory domain or $C p G$ site variation in SLC12A5, encoding the chloride transporter $\mathrm{KCC}$, in human autism and schizophrenia.

Front. Cell. Neurosci. 9:386. doi: 10.3389/fncel.2015.00386
Many encoded gene products responsible for neurodevelopmental disorders (NDs) like autism spectrum disorders (ASD), schizophrenia (SCZ), intellectual disability (ID), and idiopathic generalized epilepsy (IGE) converge on networks controlling synaptic function. An increase in KCC2 (SLC12A5) $\mathrm{Cl}^{-}$transporter activity drives the developmental GABA excitatory-inhibitory sequence, but the role of KCC2 in human NDs is essentially unknown. Here, we report two rare, non-synonymous (NS), functionally-impairing variants in the KCC2 C-terminal regulatory domain (CTRD) in human ASD (R952H and R1049C) and SCZ (R952H) previously linked with IGE and familial febrile seizures, and another novel NS KCC2 variant in ASD (R1048W) with highly-predicted pathogenicity. Exome data from 2517 simplex families in the ASD Simon Simplex Collection (SSC) revealed significantly more KCC2 CTRD variants in ASD cases than controls, and interestingly, these were more often synonymous and predicted to disrupt or introduce a CpG site. Furthermore, full gene analysis showed ASD cases are more likely to contain rare KCC2 variants affecting $\mathrm{CpG}$ sites than controls. These data suggest geneticallyencoded dysregulation of KCC2-dependent GABA signaling may contribute to multiple human NDs.

Keywords: KCC2, NKCC1, GABA, neurodevelopmental disorders, autism, schizophrenia

\section{Introduction}

Neurodevelopmental disorders (NDs) encompass a wide range of diseases, all of which feature some element of impaired brain development, and are associated with cognitive, neurological, and/or psychiatric dysfunction (Rubenstein, 2011). Common NDs include intellectual disability (ID), autism spectrum disorder (ASD), schizophrenia (SCZ), and epilepsy (Guilmatre et al., 2009; Bozzi et al., 2012), and although classified into distinct disease categories, these disorders show phenotypic overlap and shared genetic risk factors (Mitchell, 2011; Coe et al., 2012). The genetic architecture of NDs is complex, with oliogenic contributions converging on the disruption of the structure, function, and/or plasticity of neuronal networks (Pescosolido et al., 2012). Genomics has shed insight into mechanisms underlying the overlap among 
the NDs, with copy number variant, exome sequencing, and genome-wide association study data suggesting a spectrum of neurodevelopmental pathology indexed by mutational load or severity (Krystal and State, 2014). Emerging evidence has shown many of the encoded gene products responsible for individual NDs converge on a relatively limited number of protein-protein interaction networks that operate in the same molecular processes, such as those controlling synaptic structure and function (Gilman et al., 2011; Voineagu et al., 2011; O’Roak et al., 2012; EPGP Collaborative et al., 2013; de Rubeis et al., 2014; Krumm et al., 2014).

Small, diverse populations of inhibitory GABAergic interneurons regulate the activity of excitatory neurons and their involved circuits. If inhibition is impaired, disturbance in excitatory/inhibitory balance can lead to the dysfunction of cognitive processes (Braat and Kooy, 2015). A common feature among different NDs is impaired GABAergic inhibition (Hashimoto et al., 2008; Kang and Macdonald, 2009; Schmidt and Mirnics, 2014), and neuronal hyperexcitability has been implicated in the pathogenesis of ASD (Coghlan et al., 2012), SCZ (Lewis et al., 2012), Rett syndrome (Medrihan et al., 2008; Chao et al., 2010), Tourette syndrome (Kalanithi et al., 2005), tuberous sclerosis (Talos et al., 2012), and neurofibromatosis type I (Cui et al., 2008). The strong bidirectional association between NDs and epilepsy suggests impaired GABAergic inhibition as a potential pathogenic mechanism of mutual susceptibility (Tuchman and Rapin, 2002; Brooks-Kayal, 2010; Chang et al., 2011; Deidda et al., 2014).

Ionotropic $\mathrm{GABA}_{\mathrm{A}} \mathrm{Rs}$ are ligand-gated $\mathrm{Cl}^{-}$channels, and the post-synaptic response to $\mathrm{GABA}_{\mathrm{A}} \mathrm{R}$ activation is significantly modulated by the intraneuronal concentration of $\mathrm{Cl}^{-}\left(\left[\mathrm{Cl}^{-}\right]_{\mathrm{i}}\right)$. In immature neurons, $\left[\mathrm{Cl}^{-}\right]_{\mathrm{i}}$ is sufficiently high that $\mathrm{GABA}_{\mathrm{A}} \mathrm{R}$ activation triggers giant depolarizing potentials, which characterize early network activity and stimulate $\mathrm{Ca}^{2+}$-dependent synaptogenesis (Ben-Ari et al., 1989; Belhage et al., 1998). A post-natal increase in the functional expression of KCC2 (SLC12A5), a cation- $\mathrm{Cl}^{-}$ cotransporter (CCC) mediating Cl- efflux, lowers $\left[\mathrm{Cl}^{-}\right]_{\mathrm{i}}$ in post-synaptic neurons such that $\mathrm{GABA}_{\mathrm{A}} \mathrm{R}$ activation elicits membrane hyperpolarization and fast synaptic inhibition (Kaila et al., 2014). KCC2 is required for the normal developmental GABA excitatory-inhibitory sequence, and KCC2 deficiency disrupts normal brain development and results in network hyperexcitability (Hubner et al., 2001; HekmatScafe et al., 2006, 2010; Tanis et al., 2009; Bellemer et al., 2011).

Abnormal functional expression of $\mathrm{KCC} 2$ or its $\mathrm{Cl}^{-}$ importing cousin NKCC1, and associated impairment of GABA inhibition, have been documented in rodent models of multiple different NDs [see Table 1 in Deidda et al. (2014)]. For example, in mouse models of Fragile $\mathrm{X}$ syndrome, the most common genetic cause of human autism, there is a significantly delayed developmental switch to GABAergic inhibition due to prolonged elevation in neuronal $\left[\mathrm{Cl}^{-}\right]_{\mathrm{i}}$ due in part to decreased KCC2 expression (Lemonnier et al., 2013), and blockade of up-regulated NKCC1-mediated $\mathrm{Cl}^{-}$import in this context normalizes $\left[\mathrm{Cl}^{-}\right]_{\mathrm{i}}$, electrophysiological responses, and autistic-like behaviors in these mice (Tyzio et al., 2014), and improves autistic behaviors in humans (Lemonnier et al., 2012). However, the role of KCC2 in the human nervous system and in NDs is essentially unknown. Identification of such variants could elucidate the molecular pathophysiology of these diseases and identify therapeutic targets.

The KCC2 C-terminal regulatory domain (CTRD) is a critical region of transporter function, and contains multiple phosphorylated residues (such as Thr906/Thr1007 and Ser940 (reviewed in Blaesse et al., 2009; Chamma et al., 2012; Kahle et al., 2013; Medina et al., 2014); and functional domains (e.g., Acton et al., 2012) that establish contextappropriate transport activity (de Los Heros et al., 2014; see Figure 1). We recently identified an enrichment of KCC2 nonsynonymous (NS) alleles in French Canadian (FC) idiopathic generalized epilepsy (IGE) cases compared to controls that included two rare and functional IGE risk alleles (KCC2 R952H and R1049C; Kahle et al., 2014). Both of these variants decrease $\mathrm{KCC} 2$-mediated $\mathrm{Cl}^{-}$extrusion and render neuronal GABA activity more depolarized by decreasing the amount of Ser940 stimulatory phosphorylation (Kahle et al., 2014). KCC2 R952H was also identified as a cause of an inherited form of febrile seizures in an Australian family, and shown to impair dendritic spine formation (Puskarjov et al., 2014).

Here, we sought to determine if risk alleles in the KCC2 CTRD (amino acids 894-1086; NP_065759) were present in large FC cohorts of ASD, SCZ, or ID by utilizing a similar targeted genetic sequencing approach we successfully utilized for IGE (Kahle et al., 2014). We speculated that genetic mutations and/or functionally impairing variants in the KCC2 CTRD might contribute to NDs.

\section{Materials and Methods}

\section{Clinical Sampling}

The three disease cohorts of ASD, SCZ, and ID, were established as a part of the Synapse to Disease (S2D) project initiated by Dr. Guy Rouleau at Montreal Neurological Institute and McGill University in order to identify genes that cause or predispose to numerous disorders of brain development. The sample characteristics of these FC cohorts have previously been described (Gauthier et al., 2005; Hamdan et al., 2009; Awadalla et al., 2010).

\section{KCC2 C-Terminus Targeted Screening}

We implemented a targeted DNA Sanger sequencing approach to screen the $3^{\prime}$ end of SLC12A5 that encodes the CTRD of KCC2 (Kahle et al., 2014). Specifically, we targeted the coding nucleotides in exons 21-25 of SLC12A5 [NM_020708.4 (NP_065759 amino acids 894-1086) or NM_001134771 (NP_001128243 amino acids 917-1110)] by following the same protocol outlined in Kahle et al. (2014); a total of 427 ASD, 143 SCZ and 190 ID cases were screened. A total of 1214 matched controls were previously screened for mutations in the targeted region of KCC2 (Kahle et al., 2014). 
TABLE 1 | SLC12A5 variants detected in the FC ASD cohort through the targeted screening of the C-terminus.

\begin{tabular}{|c|c|c|c|c|c|c|c|c|c|}
\hline \multicolumn{3}{|c|}{ Variants detected in the screened region } & \multicolumn{3}{|c|}{ Detection of variants in Quebec ASD cohort } & \multicolumn{4}{|c|}{ FC population controls (Total: 1214 controls) } \\
\hline $\begin{array}{l}\text { NM_020708.4 } \\
\text { NP_065759 }\end{array}$ & $\begin{array}{l}\text { NM_001134771.1 } \\
\text { NP_001128243 }\end{array}$ & rs ID & $\begin{array}{c}\text { Number } \\
\text { of probands }\end{array}$ & $\begin{array}{l}\text { Number } \\
\text { of alleles }\end{array}$ & $\begin{array}{c}\text { Allele } \\
\text { frequency (\%) }\end{array}$ & $\begin{array}{l}\text { Number } \\
\text { of alleles }\end{array}$ & $\begin{array}{c}\text { Allele } \\
\text { frequency (\%) }\end{array}$ & $p$-value & $\begin{array}{l}\text { Odds } \\
\text { ratio }\end{array}$ \\
\hline $\begin{array}{l}\text { c. } 2855 \mathrm{G}>\mathrm{A} \\
\text { p.R952H }\end{array}$ & $\begin{array}{l}\text { c. } 2924 \mathrm{G}>\mathrm{A} \\
\text { p. } \mathrm{R} 975 \mathrm{H}\end{array}$ & rs142740233 & $2 / 427$ & $2 / 854$ & 0.23 & $5 / 2428$ & 0.21 & 1.00 & $\begin{array}{c}1.14 \\
\mathrm{Cl}_{95}[0.1-7.0]\end{array}$ \\
\hline $\begin{array}{l}\text { c. } 2961 \mathrm{G}>\mathrm{A} \\
\text { p.P987P }\end{array}$ & $\begin{array}{l}\text { c. } 3030 \mathrm{G}>\mathrm{A} \\
\text { p.P1010P }\end{array}$ & rs550491448 & $1 / 427$ & $1 / 854$ & 0.12 & $0 / 2428$ & 0.00 & 0.26 & $\begin{array}{c}\operatorname{Inf} \\
\mathrm{Cl}_{95}[0.1-\operatorname{Inf}]\end{array}$ \\
\hline $\begin{array}{l}\text { c.3142 C > T } \\
\text { p.R1048W }\end{array}$ & $\begin{array}{l}\text { c. } 3211 \mathrm{C}>\mathrm{T} \\
\text { p.R1071W }\end{array}$ & rs369042030 & $1 / 427$ & $1 / 854$ & 0.12 & $0 / 2428$ & 0.00 & 0.26 & $\begin{array}{c}\operatorname{Inf} \\
\mathrm{Cl}_{95}[0.1-\operatorname{Inf}]\end{array}$ \\
\hline $\begin{array}{l}\text { c. } 3145 \mathrm{C}>\mathrm{T} \\
\text { p.R1049C }\end{array}$ & $\begin{array}{l}\text { c. } 3214 \mathrm{C}>\mathrm{T} \\
\text { p.R1072C }\end{array}$ & - & $1 / 427$ & $1 / 854$ & 0.12 & $1 / 2428$ & $4.12 \times 10^{-4}$ & 0.45 & $\begin{array}{c}2.84 \\
\mathrm{Cl}_{95}[0.0-223.0]\end{array}$ \\
\hline \multicolumn{3}{|c|}{ Total number of variants detected } & 5 & 5 & - & 6 & - & 0.17 & $\begin{array}{c}2.37 \\
\mathrm{Cl}_{95}[0.6-9.4]\end{array}$ \\
\hline
\end{tabular}

\section{Protein Sequence Alignment and In Silico Prediction Programs}

ClustalW (Larkin et al., 2007) and WebLogo (Crooks et al., 2004) were used to align different orthologues of the KCC2 to determine the evolutionary conservation of the novel KCC2 variant, R1048W (Figures 1B,C). Conservation of KCC2 R952H and R1049C were previously demonstrated (Kahle et al., 2014).
Conservation of the KCC2 protein was determined by aligning the following orthologues: Homo sapiens (NP_065759), Macaca mulatta (XM_001104494.2_prot), Bos Taurus (NP_001193309), Rattus norvegicus (NP_599190), Mus musculus (NP_065066), Tetraodon nigroviridis (ENSTNIT00000021299), and Danio rerio (ENSDART00000009569). Regarding the WebLogo output, the $\mathrm{y}$-axis serves as a means of determining relative conservation
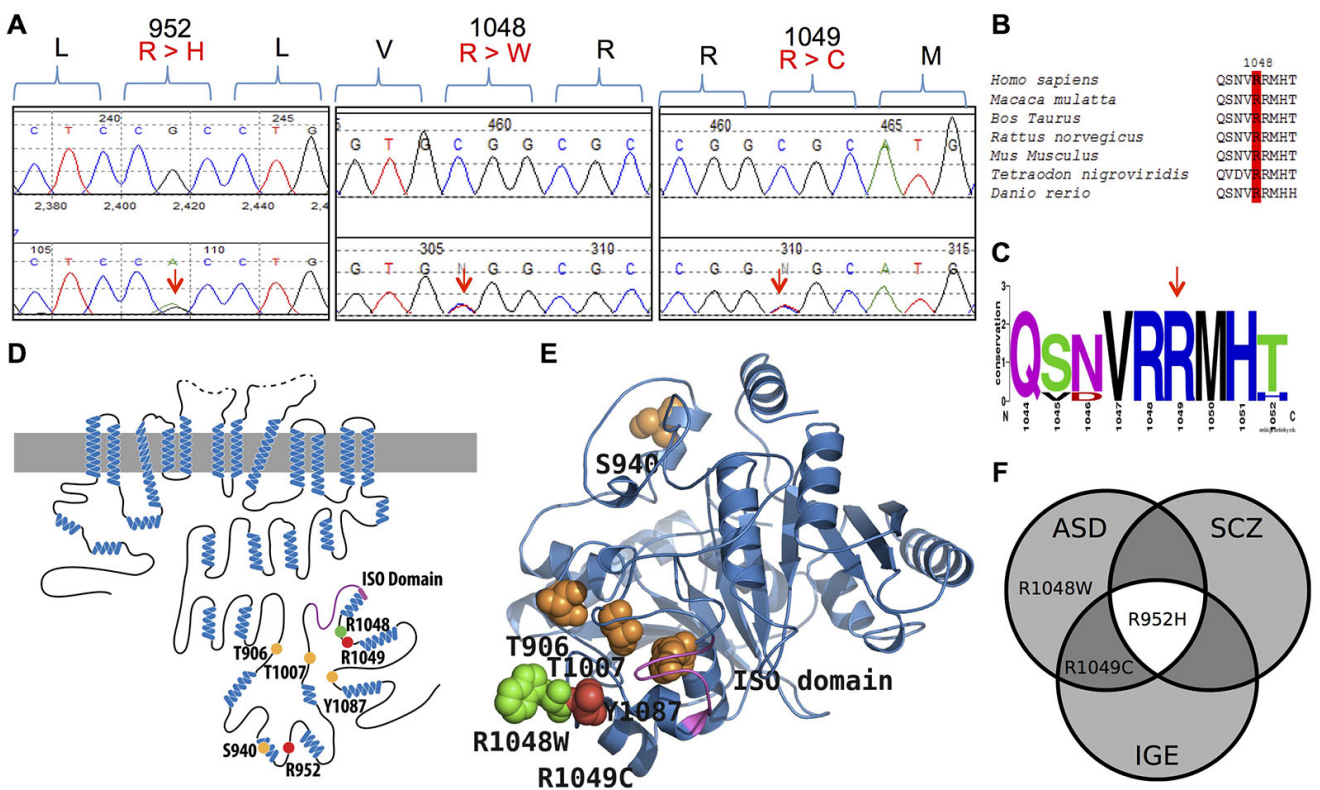

FIGURE 1 | KCC2 (SLC12A5) variants in human autism spectrum disorder (ASD) and schizophrenia (SCZ). (A) DNA chromatograms illustrating the detection of KCC2 variants in ASD (c.2855 G > A [p.R952H]; c.3145 C > T [p.R1049C]; and c.3142 C > T [p.R1048W]); and SCZ (p.R952H) via Sanger sequencing. (B,C) Evolutionary conservation of amino acid p.R1048; and conservation of amino acids p.R952 and p.R1049 shown in Kahle et al. (2014). (D) Schematic representation of KCC2 (human). Orange dots indicate the positions of the known critical phospho-regulatory residues p.T906, p.S940, p.T1007, and p.Y1087 (reviewed in Chamma et al., 2012; Kahle et al., 2013); Pink region denotes the KCC2 "ISO" domain, required for hyperpolarizing GABAergic transmission (Acton et al., 2012). Red dots depict the identified IGE mutations, p.R952 and p.R1049; green dots depict the identified ASD variants, p.R952H, p.R1049C, and p.R1048W; yellow dots indicate the identified SCZ variant p.R952H. (E) The modeled structure of the human KCC2 C-terminal domain (CTRD), based on homology modeling by I-TASSER (Roy et al., 2010) using a prokaryotic member of the CCC family (PDB code 3g40) (for details, see "Materials and Methods" Section). Color scheme same as in (D). Note the proximity of the novel p.R1048W ASD variant and the previously described KCC2 IGE variants, as well as their relation to important regulatory residues and domains. (F) Venn diagram showing overlap of KCC2 variants in multiple neurodevelopmental phenotypes (IGE, ASD, and SCZ) that exhibit dysfunctional GABA signaling (Deidda et al., 2014). 
and is not an actual measurement; the height of each stack at each amino acid position is relative to the overall conservation at that position, the height of the letters within each stack indicate the relative frequencies for each amino acid possibility, and the width of each stack corresponds to the proportion of valid readings at that position (indicating if sequence gaps exist between the shown amino acids). The effects of amino acid substitutions on protein function were predicted using MutationTaster (Schwarz et al., 2010), Panther (Mi et al., 2005), and Polyphen-2 (Adzhubei et al., 2010).

\section{Exome Sequencing Analysis}

Iossifov et al. (2014) recently reported the whole exome sequencing of 2517 ASD simplex families from the Simon Simplex Collection (SSC; Fischbach and Lord, 2010). They carried out a de novo mutation analysis that generated an extensive list of de novo variants and recurrently hit genes that could be subdivided with different clinical phenotypes (Iossifov et al., 2014). These exome sequencing data are now available through the NDAR (National Database of Autism Research); we were granted access to variant calling files to further assess SLC12A5.

Our analysis involved filtering for sample type to include only probands (.p1), accession number (NM_001134771) to include only SLC12A5, and "_par-races_" (we either selected "white, white" or "african-amer, african-amer") to include probands with either two Caucasian parents (EA ASD cases) or two African American parents (AA ASD cases), respectively. According to Supplementary Table 1 in Iossifov et al. (2014), there were 1892 EA ASD cases and 82 AA ASD cases. We carried out a rare variant $(<1 \%$ MAF) analysis; therefore, we filtered out SNPs (single nucleotide polymorphisms) with a MAF $>1 \%$ in each ethnic group. This resulted in a list of rare coding variants for the full gene and our targeted gene region. Furthermore, we used the EA and AA Exome Variant Server (EVS) data (NHLBI GO Exome Sequencing Project $)^{1}$ as our ethnic controls; there were a total of 4300 EA controls and 2203 AA controls exome sequenced. We generated lists of rare variants that were detected in each control cohort.

\section{Statistical Analysis}

All statistical genetic analysis was carried out using the program R (version 2.15.1). Fisher tests or Mantel-Haenzel Chi Squared

\footnotetext{
${ }^{1}$ http://evs.gs.washington.edu/EVS/
}

tests were carried out to generate the $p$-values and odds ratios where appropriate.

\section{Results}

Using Sanger sequencing, we examined the $3^{\prime}$ end of SLC12A5 that encodes the KCC2 CTRD (amino acids 894-1086; NP_065759) in three large FC disease cohorts of ASD, SCZ, or ID that were collected as part of the S2D project (see "Materials and Methods" Section). In contrast to our previous analysis in IGE which identified an enrichment of KCC2 NS CTRD alleles in IGE cases compared to controls ( $p$-value $=7.50 \times 10^{-3}$; Kahle et al., 2014), analysis of our initial ASD, SCZ or ID sequencing results did not show an enrichment of NS KCC2 CTRD alleles in cases (Table 1). Interestingly, however, three different heterozygous and NS KCC2 variants were detected in the ASD cohort; these included the two previously-identified IGE risk variants, $\mathrm{R} 952 \mathrm{H}$ and R1049C (Kahle et al., 2014), and R1048W (Figure 1 and Table 1).

R1048 in KCC2 is a highly conserved residue (Figure 1), and a substitution for a tryptophan at this position is predicted to be highly pathogenic using multiple in silico bioinformatics programs (Table 2). This variant is extremely rare; it was not detected in 2428 FC alleles, but this number of controls was too small to generate a significant $p$-value (Table 1). Indeed, power analysis determined that 50,000 control alleles would need to be genotyped, assuming the allele frequencies remain the same and a $p$-value of 0.0167 is significant (after a Bonferroni correction). This limitation is common when identifying rare genetic risk factors, and also relevant for the R1049C variant (Table 1), where 100,000 control alleles would need to be genotyped to reach significance. $\mathrm{R} 952 \mathrm{H}$ was previously determined to have an allele frequency of $0.66 \%$ in the FC IGE cohort (Kahle et al., 2014) compared to $0.21 \%$ in FC controls and $0.23 \%$ in the FC ASD cohort (Table 1). One SCZ patient was also determined to carry $\mathrm{R} 925 \mathrm{H}$, corresponding to an allele frequency of $0.35 \%$ (Table 3 ). Two heterozygous synonymous variants were also detected in our screening, including P987P in an ASD patient (Table 1), and D935D in an SCZ patient (Table 3).

From a functional standpoint, both R952H and R1049C impair KCC2 transporter activity (Kahle et al., 2014); they significantly decrease $\mathrm{KCC} 2$-mediated $\mathrm{Cl}^{-}$extrusion capacity in neurons, render EGly less hyperpolarized compared to WT KCC2, decrease the level of stimulatory phosphorylation of Ser940, act in a dominant-negative manner consistent with

TABLE 2 | Predicted pathogenicity of the novel KCC2 (SLC12A5) variant.

\begin{tabular}{|c|c|c|c|c|c|}
\hline \multicolumn{2}{|c|}{ Variant name } & \multicolumn{4}{|c|}{ Prediction programs } \\
\hline NM_020708.4 & NM_001134771.1 & \multicolumn{2}{|c|}{ Mutation taster } & \multirow[t]{2}{*}{ Panther } & \multirow[t]{2}{*}{ Polyphen } \\
\hline NP_065759 & NP_001128243 & & & & \\
\hline c.3142 C > T & c. $3211 \mathrm{C}>\mathrm{T}$ & Disease & P (probability): & $P_{\text {deleterious }}=0.80942$ & Possibly damaging \\
\hline p.R1048W & p.R1071W & causing* & 0.9999 & & (0.813) \\
\hline
\end{tabular}

*Predicted specifically to disrupt the function of the last cytoplasmic domain. 
TABLE 3 | SLC12A5 variants detected in the SCZ cohort through the targeted screening of the C-terminus.

\begin{tabular}{|c|c|c|c|c|c|c|c|c|}
\hline $\begin{array}{l}\text { c. } 2805 \mathrm{~T}>\mathrm{C} \\
\text { p.D935D }\end{array}$ & $\begin{array}{l}\text { c.2874 T > C rs151293924 } \\
\text { p.D958D }\end{array}$ & $1 / 143$ & $1 / 286$ & 0.35 & 0/2428 & 0.00 & 0.11 & $\begin{array}{c}\operatorname{lnf} \\
\mathrm{Cl}_{95}[0.2-\operatorname{Inf}]\end{array}$ \\
\hline $\begin{array}{l}\text { c. } 2855 \mathrm{G}>\mathrm{A} \\
\text { p. } \mathrm{R} 952 \mathrm{H}\end{array}$ & $\begin{array}{l}\text { c. } 2924 \mathrm{G}>\mathrm{A} \quad \mathrm{rs} 142740233 \\
\text { p.R975H }\end{array}$ & $1 / 143$ & $1 / 286$ & 0.35 & $5 / 2428$ & 0.21 & 0.50 & $\begin{array}{c}1.70 \\
\mathrm{Cl}_{95}[0.0-15.3]\end{array}$ \\
\hline
\end{tabular}

*A total of 6 variants were detected in FC control cohort [5 R975H and 1 R1072C (which is not shown in this table)].

the known oligomerization of KCC2 molecules, and decrease transporter plasmalemmal expression $(\mathrm{R} 952 \mathrm{H})$ or lower the intrinsic activity of transporters at the cell surface (R1049C) (Kahle et al., 2014). We anticipate these variants function similarly in ASD; however, the phenotypic outcomes of any effect of these variants are likely dependent on the combination of other risk alleles within each individual patient. Considering the proximity of R1048 to R1049, and the fact that both variants substitute an arginine, we assume the functional effects of R1048W on KCC2 would be similar to that of R1049C (Kahle et al., 2014).
Overall, the data generated from the targeted screening of $3^{\prime}$ end of SLC12A5 in FC cases and controls did not reach statistical significance, possibly due to the rare nature of the variants and the size of the FC cohorts (Table 4). However, when the SSC and EVS exome sequencing data was considered, the combined analysis indicated there was an enrichment of all coding KCC2 CTRD variants in ASD cases compared to controls $(p$-value $=0.03$; Table 4$)$. In fact, when subdividing the variants into various groups, we determined that ASD cases actually had significantly more synonymous variants compared to controls $(p$-value $=0.02)$, as well as

TABLE 4 | SLC12A5 variants detected in the FC and SSC EA and AA cohorts in the targeted region of the C-terminus.

\begin{tabular}{|c|c|c|c|c|c|c|c|c|}
\hline \multirow[b]{2}{*}{ Variant type } & \multicolumn{3}{|c|}{ Cohort } & \multirow[b]{2}{*}{$\begin{array}{c}\text { Number of rare } \\
\text { variants transported }\end{array}$} & \multirow[b]{2}{*}{$p$ value } & \multirow[b]{2}{*}{ Odds ratio } & \multicolumn{2}{|c|}{ Combined } \\
\hline & Ethnicity & Group & Size & & & & $p$ value & Odds ratio \\
\hline \multirow[t]{6}{*}{ All } & $\mathrm{FC}$ & ASD Cases & 427 & 5 & 0.17 & $2.37 \mathrm{Cl}_{95}[0.6-9.4]$ & 0.03 & $2.00 \mathrm{Cl}_{95}[1.1-3.6]$ \\
\hline & & Controls & 1214 & 6 & & & & \\
\hline & EA & ASD Cases & 1892 & 12 & 0.09 & $1.95 \mathrm{Cl}_{95}[0.8-4.5]$ & & \\
\hline & & EVS Controls & 4300 & 14 & & & & \\
\hline & $\mathrm{AA}$ & ASD Cases & 82 & 2 & 0.35 & $1.67 \mathrm{Cl}_{95}[0.2-6.8]$ & & \\
\hline & & EVS Controls & 2203 & 32 & & & & \\
\hline \multirow[t]{6}{*}{ Non-synonymous } & $\mathrm{FC}$ & ASD Cases & 427 & 4 & 0.30 & $1.90 \mathrm{Cl}_{95}[0.4-8.0]$ & 0.31 & $1.53 \mathrm{Cl}_{95}[0.8-3.1]$ \\
\hline & & Controls & 1214 & 6 & & & & \\
\hline & EA & ASD Cases & 1892 & 9 & 0.37 & $1.46 \mathrm{Cl}_{95}[0.6-3.6]$ & & \\
\hline & & EVS Controls & 4300 & 14 & & & & \\
\hline & $\mathrm{AA}$ & ASD Cases & 82 & 0 & 1.00 & $0.00 \mathrm{Cl}_{95}[0.0-29.7]$ & & \\
\hline & & EVS Controls & 2203 & 5 & & & & \\
\hline \multirow[t]{6}{*}{ Synonymous } & $\mathrm{FC}$ & ASD Cases & 427 & 1 & 0.26 & $\operatorname{lnf} \mathrm{Cl}_{95}[0.1-\operatorname{lnf}]$ & 0.02 & $4.93 \mathrm{Cl}_{95}[1.7-14.8]$ \\
\hline & & Controls & 1214 & 0 & & & & \\
\hline & EA & ASD Cases & 1892 & 3 & 0.02 & $\operatorname{lnf} \mathrm{Cl}_{95}[0.9-\operatorname{lnf}]$ & & \\
\hline & & EVS Controls & 4300 & 0 & & & & \\
\hline & $\mathrm{AA}$ & ASD Cases & 82 & 2 & 0.28 & $2.00 \mathrm{Cl}_{95}[0.2-8.1]$ & & \\
\hline & & EVS Controls & 2203 & 27 & & & & \\
\hline \multirow[t]{6}{*}{ CpG site disrupted or gained } & FC & ASD Cases & 427 & 5 & 0.17 & $2.37 \mathrm{Cl}_{95}[0.6-9.4]$ & $6.8 \times 10^{-3}$ & $2.5 \mathrm{Cl}_{95}[1.3-4.7]$ \\
\hline & & Controls & 1214 & 6 & & & & \\
\hline & EA & ASD Cases & 1892 & 11 & 0.02 & $2.78 \mathrm{Cl}_{95}[1.0-7.6]$ & & \\
\hline & & EVS Controls & 4300 & 9 & & & & \\
\hline & AA & ASD Cases & 82 & 2 & 0.31 & $1.85 \mathrm{Cl}_{95}[0.2-7.5]$ & & \\
\hline & & EVS Controls & 2203 & 29 & & & & \\
\hline \multirow[t]{6}{*}{ CpG site not disrupted or gained } & $\mathrm{FC}$ & ASD Cases & 427 & 0 & 1.00 & $0.00 \mathrm{Cl}_{95}[0.0-\mathrm{Inf}]$ & 0.71 & $0.42 \mathrm{Cl}_{95}[0.0-3.6]$ \\
\hline & & Controls & 1214 & 0 & & & & \\
\hline & EA & ASD Cases & 1892 & 1 & 0.67 & $0.45 \mathrm{Cl}_{95}[0.0-4.1]$ & & \\
\hline & & EVS Controls & 4300 & 5 & & & & \\
\hline & AA & ASD Cases & 82 & 0 & 1.00 & $0.00 \mathrm{Cl}_{95}[0.0-65.6]$ & & \\
\hline & & EVS Controls & 2203 & 3 & & & & \\
\hline
\end{tabular}


TABLE 5 | Full gene rare variant (MAF < 1\%) analysis of SLC12A5 using the SSC exome sequencing data.

\begin{tabular}{|c|c|c|c|c|c|c|c|c|}
\hline \multirow[b]{2}{*}{ Variant type } & \multicolumn{3}{|c|}{ Cohort } & \multirow[b]{2}{*}{$\begin{array}{c}\text { Number of rare } \\
\text { variants transported }\end{array}$} & \multirow[b]{2}{*}{$p$ value } & \multirow[b]{2}{*}{ Odds ratio } & \multicolumn{2}{|c|}{ Combined } \\
\hline & Ethnicity & Group & Size & & & & $p$ value & Odds ratio \\
\hline \multirow[t]{4}{*}{ All } & EA & ASD Cases & 1892 & 50 & 1.00 & $1.00 \mathrm{Cl}_{95}[0.7-1.4]$ & 0.76 & $1.06 \mathrm{Cl}_{95}[0.8-1.4]$ \\
\hline & & EVS Controls & 4300 & 114 & & & & \\
\hline & AA & ASD Cases & 82 & 9 & 0.30 & $1.44 \mathrm{Cl}_{95}[0.6-2.9]$ & & \\
\hline & & EVS Controls & 2203 & 168 & & & & \\
\hline \multirow[t]{4}{*}{ Non-synonymous } & EA & ASD Cases & 1892 & 21 & 0.68 & $1.11 \mathrm{Cl}_{95}[0.6-1.9]$ & 0.98 & $1.04 \mathrm{Cl}_{95}[0.6-1.8]$ \\
\hline & & EVS Controls & 4300 & 43 & & & & \\
\hline & AA & ASD Cases & 82 & 0 & 1.00 & $0.00 \mathrm{Cl}_{95}[0.0-4.8]$ & & \\
\hline & & EVS Controls & 2203 & 23 & & & & \\
\hline \multirow[t]{4}{*}{ Synonymous } & EA & ASD Cases & 1892 & 29 & 0.73 & $1.08 \mathrm{Cl}_{95}[0.7-1.7]$ & 0.38 & $1.20 \mathrm{Cl}_{95}[0.8-1.8]$ \\
\hline & & EVS Controls & 4300 & 61 & & & & \\
\hline & AA & ASD Cases & 82 & 9 & 0.18 & $1.67 \mathrm{Cl}_{95}[0.7-3.4]$ & & \\
\hline & & EVS Controls & 2203 & 145 & & & & \\
\hline \multirow[t]{4}{*}{ CpG site disrupted or gained } & EA & ASD Cases & 1892 & 41 & 0.22 & $1.29 \mathrm{Cl}_{95}[0.9-1.9]$ & 0.09 & $1.37 \mathrm{Cl}_{95}[1.0-1.9]$ \\
\hline & & EVS Controls & 4300 & 72 & & & & \\
\hline & $\mathrm{AA}$ & ASD Cases & 82 & 8 & 0.15 & $1.76 \mathrm{Cl}_{95}[0.7-3.7]$ & & \\
\hline & & EVS Controls & 2203 & 122 & & & & \\
\hline \multirow[t]{4}{*}{ CpG site not disrupted or gained } & EA & ASD Cases & 1892 & 9 & 0.05 & $0.5 \mathrm{Cl}_{95}[0.2-1.0]$ & 0.06 & $0.50 \mathrm{Cl}_{95}[0.3-1.0]$ \\
\hline & & EVS Controls & 4300 & 42 & & & & \\
\hline & AA & ASD Cases & 82 & 1 & 1.00 & $0.58 \mathrm{Cl}_{95}[0.0-3.5]$ & & \\
\hline & & EVS Controls & 2203 & 46 & & & & \\
\hline
\end{tabular}

variants that either disrupted or introduced a CpG site $(p$ value $=6.8 \times 10^{-3}$; Table 4). Upon full gene analysis (using solely exome sequencing data), ASD cases were determined to have a higher percentage of rare SLC12A5 variants that affect a CpG site compared to controls (Tables 5,6), suggesting a possible epigenetic effect on gene expression through variation in methylation patterns.

\section{Discussion}

The identification of KCC2 NS genetic variants in ASD and SCZ cases that involve evolutionary conserved residues, are predicted to be pathogenic, and have either previously been shown [KCC2 R952H and R1049C (Kahle et al., 2014; Puskarjov et al., 2014)] or anticipated (KCC2 R1048W) to impact transporter function, trafficking, and/or regulatory phosphorylation, suggest that genetically-encoded impairment of KCC2 function may be risk factors for, or contribute to the pathogenesis of, human ASD and SCZ. Overall, these data are the first to describe functional KCC2 genetic variants in human psychiatric disease, and suggest a compelling genetic overlap among distinct NDs. Furthermore, we show that $\mathrm{CpG}$ sites in the targeted-screened $3^{\prime}$ end of
SLC12A5, as well as in the entire gene, are more commonly affected (i.e., disrupted or gained) in ASD cases compared to controls.

Genetic links among the different NDs have been previously shown. For example, chromosome 1q21.1 microdeletions exist in both ID and SCZ, and, interestingly, are often inherited from an unaffected or a mildly affected parent (Christiansen et al., 2004; Brunetti-Pierri et al., 2008; International-SchizophreniaConsortium, 2008; Mefford et al., 2008; Stefansson et al., 2008). Duplications of this region are also associated with mild to moderate ID and ASD (Brunetti-Pierri et al., 2008; Mefford et al., 2008). Deletions of chromosome 16p13.11 have been associated with ID and ASD (Ullmann et al., 2007), and epilepsy (Heinzen et al., 2010; de Kovel et al., 2010), and duplications of this region have been documented in ID (Ullmann et al., 2007; Mefford et al., 2009), ASD (Ullmann et al., 2007) and SCZ (Kirov et al., 2009). In addition, mutations in MECP2 [OMIM 300005] (Lam et al., 2000) and SLC6A8 [OMIM 300036] (Salomons et al., 2001) have been found in both ID and ASD; and, mutations in SHANK3 [OMIM 606230] have been identified in ASD (Durand et al., 2007), SCZ (Gauthier et al., 2010) and nonsyndromic ID cohorts (Hamdan et al., 2011). The

TABLE 6 | ASD case/control comparisons of the total number of variants that affect a CpG site vs. do not affect a CpG site from the full gene analysis.

\begin{tabular}{|c|c|c|c|c|c|c|c|c|c|c|}
\hline \multirow{2}{*}{\multicolumn{2}{|c|}{ Cohort }} & \multirow[t]{2}{*}{$\begin{array}{l}\text { Total number of rare } \\
\text { variants in SLC12A5 }\end{array}$} & \multicolumn{2}{|c|}{$\begin{array}{l}\text { Variants that disrupt } \\
\text { or gain a } \mathrm{CpG} \text { site }\end{array}$} & \multicolumn{2}{|c|}{$\begin{array}{l}\text { Variants that do not disrupt } \\
\text { or gain a CpG site }\end{array}$} & \multirow[b]{2}{*}{$p$ value } & \multirow[b]{2}{*}{ Odds ratio } & \multicolumn{2}{|r|}{ Combined } \\
\hline & & & Number & Percentage (\%) & Number & Percentage (\%) & & & $p$ value & Odds ratio \\
\hline \multirow[t]{2}{*}{ EA } & ASD Cases & 50 & 41 & 82 & 9 & 18 & 0.02 & $2.64 \mathrm{Cl}_{95}[1.1-6.8]$ & 0.01 & $2.71 \mathrm{Cl}_{95}[1.3-5.8]$ \\
\hline & EVS Controls & 114 & 72 & 63 & 42 & 37 & & & & \\
\hline & ASD Cases & 9 & 8 & 89 & 1 & 11 & 0.45 & $3.00 \mathrm{Cl}_{95}[0.4-136.6]$ & & \\
\hline & EVS Controls & 168 & 122 & 73 & 46 & 38 & & & & \\
\hline
\end{tabular}


impact of de novo SNVs (single nucleotide variants) on sporadic forms of common NDs have also been increasingly appreciated (Vissers et al., 2010; Girard et al., 2011; O’Roak et al., 2011, 2012; Xu et al., 2011; Iossifov et al., 2012; Neale et al., 2012; Sanders et al., 2012), and de novo ASD mutations have been identified in genes previously associated with other NDs, such as FOXP1 [OMIM 605515], GRIN2B [OMIM 138252], SCN1A [OMIM 182389], and LAMC3 [OMIM 604349] (O’Roak et al., 2011). No de novo variants were detected in this study.

Identifying rare variants that are associated with a complex trait is most currently performed through whole-exome sequencing since there is a potential to identify many genes that underlie the trait at a substantially lower cost compared to whole-genome sequencing; plus, exome variants offer a clear-cut functional annotation that can be predicted through many in silico bioinformatics programs with an accuracy of $\sim 80 \%$ (Kiezun et al., 2012). However, with exome sequencing, a $p$-value of less than $2.5 \times 10^{-6}$ is required to reach genome-wide significance; this value accounts for multiple testing by making a Bonferroni correction for 20,000 independent tests (1 test for each gene in the genome). Such a threshold is very conservative and unless a study is extremely large, significant $p$-values will not be reached. In fact, current exome sequencing studies of complex traits are under-powered since, at minimum, 10,000 individuals with a distinct phenotype are needed in order to achieve the necessary power (Kryukov et al., 2009; Kiezun et al., 2012). Furthermore, rare variants should be combined in a gene (or pathway) during association tests in order to reach sufficient power (Purcell et al., 2003; Kiezun et al., 2012).

A true understanding of how risk alleles interact and contribute to disease is yet to come. In a polygenic or oligogenic disease model, causality cannot be assigned to any one variant, but rather results from an individual's variant pattern (Klassen et al., 2011). A recent exome sequencing paper aimed to demonstrate the polygenic burden of rare disruptive mutations in SCZ by noting the disruptive mutations that were distributed across many genes as well as enriched gene sets (Purcell et al., 2014). The ultimate goal is to identify all risk variants and to establish a computational modeling of biological networks in order to improve risk predictions based on a combination of alleles. Interestingly, Kiezun et al. (2012) noted that no individual gene-based test achieved significance after correction for multiple testing, again reiterating the need to increase sample size and/or take more targeted screening approaches to minimize multiple testing.

Here, we utilized a hypothesis-driven, targeted sequencing approach to search for variation in the KCC2 CTRD in different NDs given the known neurophysiological importance of this gene (Gagnon and Delpire, 2013), and the demonstrated critical role of our targeted region for the functional regulation of synapses (Chamma et al., 2012; Kahle et al., 2013). This approach previously enabled us to simplify the statistical analysis to identify the enrichment of NS alleles in the KCC2 CTRD in IGE cases vs. controls $\left(p\right.$-value $=7.50 \times 10^{-3}$; Kahle et al., 2014). Rare variation is enriched for evolutionarily deleterious variants, and we demonstrated that the KCC2 IGE variants (R952H and R1049C) impaired KCC2 function (Kahle et al., 2014). The initial targeted screening of the KCC2 CTRD in the FC cohort of ASD, SCZ, and ID did not generate any significant associations; however, it revealed that the functional variants overlap across different NDs, suggesting a role in disease pathogenesis, and the effects of these variants are likely dependent on the combination of other alleles within each individual. After combining our initial findings with the results of other exome sequencing projects (Iossifov et al., 2014), we were able to generate improved $p$-values due to the larger sample sets. It was after this analysis that a statistically significant excess of KCC2 CTRD variants in the targeted region was identified in ASD cases compared to controls, as well as an increase of variants that affected CpG sites. It should be noted that the authors recognize the disadvantages of comparing different exome sequencing data sets (SSC and EVS) that were analyzed using different pipelines; replication studies are warranted.

What is the functional impact of the discovered KCC2 variants? The KCC2 R952H and R1049C variants significantly decrease $\mathrm{KCC} 2$-mediated $\mathrm{Cl}^{-}$extrusion capacity in neurons, render $\mathrm{E}_{G l y}$ less hyperpolarized compared to WT KCC2, decrease the level of KCC2 Ser940 phosphorylation, act in a dominantnegative manner, and decrease transporter plasmalemmal expression $(\mathrm{R} 952 \mathrm{H})$ or lower the intrinsic activity of transporters at the cell surface (R1049C). KCC2 R952H was also shown to substantially decrease dendritic spine density and alter spine morphology (Puskarjov et al., 2014). Given the evolutionary conservation of KCC2 R1048, the predicted pathogenicity of the R1048W substitution by multiple in silico algorithms, and the proximity of this variation to R1049, we anticipate the R1048W KCC2 variant detected in ASD, like R1049C, alters the intrinsic activity of KCC2 transporters at the cell surface. The clustering of the R1048 and R1049 variants suggests this region of KCC2 is particularly important for transporter regulation. Consistent with this is the proximity of the KCC2 "ISO" domain, encoded in amino acids 1022-1037, which is required for isotonic KCC2mediated hyperpolarizing GABAergic transmission (Acton et al., 2012). These variants might change $\mathrm{C}$-terminal protein structure and alter the function of the "ISO" domain, perhaps by disrupting the binding of key associated regulatory molecules.

From a pathophysiological standpoint, decreased KCC2mediated $\mathrm{Cl}^{-}$efflux in individuals carrying the KCC2 R952H, R1048W, and R1049C variants would be anticipated to increase intracellular $\left[\mathrm{Cl}^{-}\right]$, raising the $\mathrm{Cl}^{-}$reversal potential $\left(\mathrm{E}_{C l}\right)$ to less hyperpolarized potentials, and compromising $\mathrm{GABA}_{\mathrm{A}} \mathrm{R}$ mediated hyperpolarizing inhibition. In humans, KCC2 is developmentally upregulated, with low expression in utero, a rapid increase in expression around 40 postconceptional weeks, and progressively increasing levels of expression into adulthood (Dzhala et al., 2005). This pattern of expression drives the developmental switch of GABAergic signaling from depolarizing in early development to hyperpolarizing in adulthood, but the precise role of KCC2 or its disruption in neurodevelopment is unclear. The progressive developmental increase in KCC2 expression into adulthood might be expected to amplify the functional effects of KCC2 variants on CNS function over time. This may correlate with the age of onset of these neuropsychiatric disorders, as clinical symptomatology might manifest only after 
years of neurodevelopment over which deficits in KCC2 activity relative to normal become more pronounced. Further studies are indicated to explore this hypothesis.

The effects of KCC2 variants identified in this study might be similar, though less potent in magnitude given their heterozygousity, to phenotypes observed in mice with complete knockout or mild dysfunction of KCC2. Mice with complete KCC2 knockout die at birth from profound motor deficits that abolish respiratory function (Hekmat-Scafe et al., 2006, 2010; Tanis et al., 2009; Bellemer et al., 2011), but, interestingly, mice expressing hypomorphic alleles that reduce but do not abolish KCC2 activity demonstrate anxiety-like behavior, impaired spatial learning, and decreased seizure threshold (Woo et al., 2002; Tornberg et al., 2005; Zhu et al., 2008). Together, these data indicate that regulation of $\mathrm{Cl}^{-}$ homeostasis and GABAergic signaling by KCC2 plays a role in multiple functional systems of the CNS. These studies have also demonstrated that genetic KCC2 knockdown is not accompanied by compensatory changes in the expression of NKCC1 or other KCC isoforms, although post-translational compensatory regulation (e.g., phosphorylation) cannot be ruled out (Hubner et al., 2001; Woo et al., 2002; Tornberg et al., 2005).

Compellingly, CpG sites in the screened $3^{\prime}$ end of SLC12A5, as well as in the entire gene, are more commonly affected (i.e., disrupted or gained) in ASD cases compared to controls. Generally, DNA methylation occurs at CpG sites and plays a role in gene expression by suppressing gene transcription. Therefore, differences in methylation patterns between cases and controls could result in different gene expression patterns that increase risk to $\mathrm{ASD}$. $\mathrm{CpG}$ islands, regions of $\mathrm{CpG}$ clusters that are associated with genes, are generally involved in transcription activation. Interestingly, there is a CpG island of $\sim 2000 \mathrm{bp}$

\section{References}

Acton, B. A., Mahadevan, V., Mercado, A., Uvarov, P., Ding, Y., Pressey, J., et al. (2012). Hyperpolarizing GABAergic transmission requires the KCC2 Cterminal ISO domain. J. Neurosci. 32, 8746-8751. doi: 10.1523/jneurosci.608911.2012

Adzhubei, I. A., Schmidt, S., Peshkin, L., Ramensky, V. E., Gerasimova, A., Bork, P., et al. (2010). A method and server for predicting damaging missense mutations. Nat. Methods. 7, 248-249. doi: 10.1038/nmeth 0410-248

Awadalla, P., Gauthier, J., Myers, R. A., Casals, F., Hamdan, F. F., Griffing, A. R., et al. (2010). Direct measure of the de novo mutation rate in autism and schizophrenia cohorts. Am. J. Hum. Genet. 87, 316-324. doi: 10.1016/j.ajhg. 2010.07.019

Belhage, B., Hansen, G. H., Elster, L., and Schousboe, A. (1998). Effects of gammaaminobutyric acid (GABA) on synaptogenesis and synaptic function. Perspect Dev. Neurobiol. 5, 235-246.

Bellemer, A., Hirata, T., Romero, M. F., and Koelle, M. R. (2011). Two types of chloride transporters are required for $\mathrm{GABA}(\mathrm{A})$ receptor-mediated inhibition in C. elegans. EMBO. J. 30, 1852-1863. doi: 10.1038/emboj.2011.83

Ben-Ari, Y., Cherubini, E., Corradetti, R., and Gaiarsa, J. L. (1989). Giant synaptic potentials in immature rat CA3 hippocampal neurones. J. Physiol. 416, 303-325. doi: 10.1113/jphysiol.1989.sp017762

Blaesse, P., Airaksinen, M. S., Rivera, C., and Kaila, K. (2009). Cation-chloride cotransporters and neuronal function. Neuron. 61, 820-838. doi: 10.1016/j. neuron.2009.03.003

Bozzi, Y., Casarosa, S., and Caleo, M. (2012). Epilepsy as a neurodevelopmental disorder. Frontiers in Psychiatry. 3:19. doi: 10.3389/fpsyt.2012.00019 at the $3^{\prime}$ end of SLC12A5 that partially overlaps with our targeted-screened region. Furthermore, despite the fact that the variants detected in our targeted-screened region are outside that specific $\mathrm{CpG}$ island, most methylation differences between tissues and, perhaps even between patients and controls, actually occur at $\mathrm{CpG}$ sites at a short distance from the actual CpG island (Irizarry et al., 2009). It would be interesting to screen the entire SLC12A5 locus (coding and non-coding regions) to determine if non-coding variants contribute towards a stronger association in ASD cases and controls. Additionally, carrying out the same analysis in an SCZ case/control cohort would be valuable.

Lastly, our results are interesting given the recent data from the Fragile $\mathrm{X}$ and valproate mouse models of autism, which demonstrate an abnormally prolonged elevation of $\left[\mathrm{Cl}^{-}\right]_{\mathrm{i}}$ in developing CNS neurons that delays the normal ontogenic switch to GABA inhibition (He et al., 2014). Maternal oxytocin during delivery normally mediates the hyperpolarization of $\mathrm{E}_{\mathrm{GABA}}$, but this effect is abolished in the these models (Tyzio et al., 2014). Our data here suggest a compelling hypothesis that abnormally delayed KCC2-mediated $\mathrm{Cl}^{-}$extrusion during the developmental GABA excitatory-inhibitory sequence might be a genetically programmed factor contributing to ASD. Further investigation into the roles of KCC2 in ASD and SCZ, and potentially other NDs, may offer new therapeutic strategies.

\section{Acknowledgments}

The authors thank JingJing Duan (Harvard Medical School, Boston, MA), Jin Zhang (Harvard Medical School, Boston, MA), and Jinwei Zhang (University of Dundee, Dundee, Scotland) for their technical support and assistance in conducting the experiments described in this study.

Braat, S., and Kooy, R. F. (2015). The GABA Receptor as a Therapeutic Target for Neurodevelopmental Disorders. Neuron. 86, 1119-1130. doi: 10.1016/j.neuron. 2015.03.042

Brooks-Kayal, A. (2010). Epilepsy and autism spectrum disorders: Are there common developmental mechanisms? Brain and Development. 32, 731-738. doi: 10.1016/j.braindev.2010.04.010

Brunetti-Pierri, N., Berg, J. S., Scaglia, F., Belmont, J., Bacino, C. A., Sahoo, T., et al. (2008). Recurrent reciprocal 1q21.1 deletions and duplications associated with microcephaly or macrocephaly and developmental and behavioral abnormalities. Nat. Genet. 40, 1466-1471. doi: 10.1038/ng.279

Chamma, I., Chevy, Q., Poncer, J. C., and Lévi, S. (2012). Role of the neuronal K$\mathrm{Cl}$ co-transporter KCC2 in inhibitory and excitatory neurotransmission. Front. Cell. Neurosci. 6:5. doi: 10.3389/fncel.2012.00005

Chang, Y. T., Chen, P. C., Tsai, I. J., Sung, F. C., Chin, Z. N., Kuo, H. T., et al. (2011). Bidirectional relation between schizophrenia and epilepsy: a population-based retrospective cohort study. Epilepsia. 52, 2036-2042. doi: 10. 1111/j.1528-1167.2011.03268.x

Chao, H. T., Chen, H., Samaco, R. C., Xue, M., Chahrour, M., Yoo, J., et al. (2010). Dysfunction in GABA signalling mediates autism-like stereotypies and Rett syndrome phenotypes. Nature. 468, 263-269. doi: 10.1038/nature 09582

Christiansen, J., Dyck, J. D., Elyas, B. G., Lilley, M., Bamforth, J. S., Hicks, M., et al. (2004). Chromosome 1q21.1 contiguous gene deletion is associated with congenital heart disease. Circ. Res. 94, 1429-1435. doi: 10.1161/01.res. $0000130528.72330 .5 \mathrm{c}$

Coe, B. P., Girirajan, S., and Eichler, E. E. (2012). The genetic variability and commonality of neurodevelopmental disease. Am. J. Med. Genet. C. Semin. Med. Genet. 160C, 118-129. doi: 10.1002/ajmg.c.31327 
Coghlan, S., Horder, J., Inkster, B., Mendez, M. A., Murphy, D. G., and Nutt, D. J. (2012). GABA system dysfunction in autism and related disorders: From synapse to symptoms. Neurosci. Biobehav. Rev. 36, 2044-2055. doi: 10.1016/j. neubiorev.2012.07.005

Crooks, G. E., Hon, G., Chandonia, J. M., and Brenner, S. E. (2004). WebLogo: a sequence logo generator. Genome Res. 14, 1188-1190. doi: 10.1101/gr.849004

Cui, Y., Costa, R. M., Murphy, G. G., Elgersma, Y., Zhu, Y., Gutmann, D. H., et al. (2008). Neurofibromin regulation of ERK signaling modulates GABA release and learning. Cell. 135, 549-560. doi: 10.1016/j.cell.2008.09.060

de Kovel, C. G., Trucks, H., Helbig, I., Mefford, H. C., Baker, C., Leu, C., et al. (2010). Recurrent microdeletions at 15q11.2 and 16p13.11 predispose to idiopathic generalized epilepsies. Brain. 133, 23-32. doi: 10.1093/brain/awp262

de Los Heros, P., Alessi, D. R., Gourlay, R., Campbell, D. G., Deak, M., Macartney, T. J., et al. (2014). The WNK-regulated SPAK/OSR1 kinases directly phosphorylate and inhibit the $\mathrm{K}+-\mathrm{Cl}-$ co-transporters. Biochem. J. 458, 559-573. doi: 10.1042/bj20131478

de Rubeis, S., He, X., Goldberg, A. P., Poultney, C. S., Samocha, K., Cicek, A. E., et al. (2014). Synaptic, transcriptional and chromatin genes disrupted in autism. Nature. 515, 209-215. doi: 10.1038/nature13772

Deidda, G., Bozarth, I. F., and Cancedda, L. (2014). Modulation of GABAergic transmission in development and neurodevelopmental disorders: investigating physiology and pathology to gain therapeutic perspectives. Front. Cell. Neurosci. 8:119. doi: 10.3389/fncel.2014.00119

Durand, C. M., Betancur, C., Boeckers, T. M., Bockmann, J., Chaste, P., Fauchereau, F., et al. (2007). Mutations in the gene encoding the synaptic scaffolding protein SHANK3 are associated with autism spectrum disorders. Nat. Genet. 39, 25-27. doi: 10.1038/ng1933

Dzhala, V. I., Talos, D. M., Sdrulla, D. A., Brumback, A. C., Mathews, G. C., Benke, T. A., et al. (2005). NKCC1 transporter facilitates seizures in the developing brain. Nat. Med. 11, 1205-1213. doi: 10.1038/nm1301

EPGP Collaborative, Abou-Khalil, B., Alldredge, B., Bautista, J., Berkovic, S., Bluvstein, J., et al. (2013). The epilepsy phenome/genome project. Clin. Trials. 10, 568-586. doi: 10.1177/1740774513484392

Fischbach, G. D., and Lord, C. (2010). The Simons Simplex Collection: a resource for identification of autism genetic risk factors. Neuron. 68, 192-195. doi: 10. 1016/j.neuron.2010.10.006

Gagnon, K. B., and Delpire, E. (2013). Physiology of SLC12 transporters: lessons from inherited human genetic mutations and genetically engineered mouse knockouts. Am. J. Physiol. Cell. Physiol. 304, C693-C714. doi: 10.1152/ajpcell. 00350.2012

Gauthier, J., Bonnel, A., St-Onge, J., Karemera, L., Laurent, S., Mottron, L., et al. (2005). NLGN3/NLGN4 gene mutations are not responsible for autism in the Quebec population. Am. J. Med. Genet. B. Neuropsychiatr. Genet. 132B, 74-75. doi: 10.1002/ajmg.b.30066

Gauthier, J., Champagne, N., Lafreniére, R. G., Xiong, L., Spiegelman, D., Brustein, E., et al. (2010). De novo mutations in the gene encoding the synaptic scaffolding protein SHANK3 in patients ascertained for schizophrenia. Proc. Natl. Acad. Sci. U. S. A. 107, 7863-7868. doi: 10.1073/pnas.09062 32107

Gilman, S. R., Iossifov, I., Levy, D., Ronemus, M., Wigler, M., and Vitkup, D. (2011). Rare de novo variants associated with autism implicate a large functional network of genes involved in formation and function of synapses. Neuron. 70, 898-907. doi: 10.1016/j.neuron.2011.05.021

Girard, S. L., Gauthier, J., Noreau, A., Xiong, L., Zhou, S., Jouan, L., et al. (2011). Increased exonic de novo mutation rate in individuals with schizophrenia. Nat. Genet. 43, 860-863. doi: 10.1038/ng.886

Guilmatre, A., Dubourg, C., Mosca, A. L., Legallic, S., Goldenberg, A., DrouinGarraud, V., et al. (2009). Recurrent rearrangements in synaptic and neurodevelopmental genes and shared biologic pathways in schizophrenia, autism and mental retardation. Arch. Gen. Psychiatry. 66, 947-956. doi: 10. 1001/archgenpsychiatry.2009.80

Hamdan, F. F., Gauthier, J., Araki, Y., Lin, D. T., Yoshizawa, Y., Higashi, K., et al. (2011). Excess of de novo deleterious mutations in genes associated with glutamatergic systems in nonsyndromic intellectual disability. Am. J. Hum. Genet. 88, 306-316. doi: 10.1016/j.ajhg.2011.02.001

Hamdan, F. F., Gauthier, J., Spiegelman, D., Noreau, A., Yang, Y., Pellerin, S., et al. (2009). Mutations in SYNGAP1 in autosomal nonsyndromic mental retardation. N. Engl. J. Med. 360, 599-605. doi: 10.1056/nejmoa0805392
Hashimoto, T., Arion, D., Unger, T., Maldonado-Aviles, J. G., Morris, H. M., Volk, D. W., et al. (2008). Alterations in GABA-related transcriptome in the dorsolateral prefrontal cortex of subjects with schizophrenia. Mol. Psychiatry. 13, 147-161. doi: 10.1038/sj.mp.4002011

He, Q., Nomura, T., Xu, J., and Contractor, A. (2014). The developmental switch in GABA polarity is delayed in fragile X mice. J. Neurosci. 34, 446-450. doi: 10. 1523/jneurosci.4447-13.2014

Heinzen, E. L., Radtke, R. A., Urban, T. J., Cavalleri, G. L., Depondt, C., Need, A. C., et al. (2010). Rare deletions at 16p13.11 predispose to a diverse spectrum of sporadic epilepsy syndromes. Am. J. Hum .Genet. 86, 707-718. doi: 10.1016/j. ajhg.2010.03.018

Hekmat-Scafe, D. S., Lundy, M. Y., Ranga, R., and Tanouye, M. A. (2006). Mutations in the $\mathrm{K}+/ \mathrm{Cl}$ - cotransporter gene kazachoc $(\mathrm{kcc})$ increase seizure susceptibility in Drosophila. J. Neurosci. 26, 8943-8954. doi: 10.1523/jneurosci. 4998-05.2006

Hekmat-Scafe, D. S., Mercado, A., Fajilan, A. A., Lee, A. W., Hsu, R., Mount, D. B. et al. (2010). Seizure sensitivity is ameliorated by targeted expression of K+$\mathrm{Cl}$ - cotransporter function in the mushroom body of the Drosophila brain. Genetics. 184, 171-183. doi: 10.1534/genetics.109.109074

Hubner, C. A., Stein, V., Hermans-Borgmeyer, I., Meyer, T., Ballanyi, K., and Jentsch, T. J. (2001). Disruption of KCC2 reveals an essential role of K-Cl cotransport already in early synaptic inhibition. Neuron. 30, 515-524. doi: 10. 1016/s0896-6273(01)00297-5

International-Schizophrenia-Consortium. (2008). Rare chromosomal deletions and duplications increase risk of schizophrenia. Nature. 455, 237-241. doi: 10. 1038/nature07239

Iossifov, I., O’roak, B. J., Sanders, S. J., Ronemus, M., Krumm, N., Levy, D., et al (2014). The contribution of de novo coding mutations to autism spectrum disorder. Nature. 515, 216-221. doi: 10.1038/nature13908

Iossifov, I., Ronemus, M., Levy, D., Wang, Z., Hakker, I., Rosenbaum, J., et al. (2012). De novo gene disruptions in children on the autistic spectrum. Neuron. 74, 285-299. doi: 10.1016/j.neuron.2012.04.009

Irizarry, R. A., Ladd-Acosta, C., Wen, B., Wu, Z., Montano, C., Onyango, P., et al. (2009). The human colon cancer methylome shows similar hypo- and hypermethylation at conserved tissue-specific CpG island shores. Nat. Genet. 41, 178-186. doi: 10.1038/ng.298

Kahle, K. T., Deeb, T. Z., Puskarjov, M., Silayeva, L., Liang, B., Kaila, K., et al. (2013). Modulation of neuronal activity by phosphorylation of the K-Cl cotransporter KCC2. Trends Neurosci. 36, 726-737. doi: 10.1016/j.tins.2013. 08.006

Kahle, K. T., Merner, N. D., Friedel, P., Silayeva, L., Liang, B., Khanna, A., et al. (2014). Genetically encoded impairment of neuronal KCC2 cotransporter function in human idiopathic generalized epilepsy. EMBO Rep. 15, 766-774. doi: 10.15252/embr.201438840

Kaila, K., Price, T. J., Payne, J. A., Puskarjov, M., and Voipio, J. (2014). Cationchloride cotransporters in neuronal development, plasticity and disease. Nat Rev. Neurosci. 15, 637-654. doi: 10.1038/nrn3819

Kalanithi, P. S. A., Zheng, W., Kataoka, Y., Difiglia, M., Grantz, H., Saper, C. B., et al. (2005). Altered parvalbumin-positive neuron distribution in basal ganglia of individuals with Tourette syndrome. Proc. Natl. Acad. Sci. U S A 102, 13307-13312. doi: 10.1073/pnas.0502624102

Kang, J. Q., and Macdonald, R. L. (2009). Making sense of nonsense GABA(A) receptor mutations associated with genetic epilepsies. Trends Mol. Med. 15, 430-438. doi: 10.1016/j.molmed.2009.07.003

Kiezun, A., Garimella, K., Do, R., Stitziel, N. O., Neale, B. M., Mclaren, P. J., et al. (2012). Exome sequencing and the genetic basis of complex traits. Nat. Genet 44, 623-630. doi: 10.1038/ng.2303

Kirov, G., Grozeva, D., Norton, N., Ivanov, D., Mantripragada, K. K., Holmans, P., et al. (2009). Support for the involvement of large copy number variants in the pathogenesis of schizophrenia. Hum. Mol. Genet. 18, 1497-1503. doi: 10. 1093/hmg/ddp043

Klassen, T., Davis, C., Goldman, A., Burgess, D., Chen, T., Wheeler, D., et al. (2011). Exome sequencing of ion channel genes reveals complex profiles confounding personal risk assessment in epilepsy. Cell. 145, 1036-1048. doi: 10. 3410/f.12207957.13373055

Krumm, N., O'roak, B. J., Shendure, J., and Eichler, E. E. (2014). A de novo convergence of autism genetics and molecular neuroscience. Trends Neurosci. 37, 95-105. doi: 10.1016/j.tins.2013.11.005 
Krystal, J. H., and State, M. W. (2014). Psychiatric disorders: diagnosis to therapy. Cell. 157, 201-214. doi: 10.1016/j.cell.2014.02.042

Kryukov, G. V., Shpunt, A., Stamatoyannopoulos, J. A., and Sunyaev, S. R. (2009). Power of deep, all-exon resequencing for discovery of human trait genes. Proc. Natl. Acad. Sci. U. S. A. 106, 3871-3876. doi: 10.1073/pnas.08128 24106

Lam, C. W., Yeung, W. L., Ko, C. H., Poon, P. M., Tong, S. F., Chan, K. Y., et al. (2000). Spectrum of mutations in the MECP2 gene in patients with infantile autism and Rett syndrome. J. Med. Genet. 37:E41. doi: 10.1136/jmg.37.12.e41

Larkin, M. A., Blackshields, G., Brown, N. P., Chenna, R., Mcgettigan, P. A., Mcwilliam, H., et al. (2007). Clustal W and Clustal X version 2.0. Bioinformatics. 23, 2947-2948. doi: 10.1093/bioinformatics/btm 404

Lemonnier, E., Degrez, C., Phelep, M., Tyzio, R., Josse, F., Grandgeorge, M., et al. (2012). A randomised controlled trial of bumetanide in the treatment of autism in children. Transl. Psychiatry. 2:e197. doi: 10.1038/tp.2012.124

Lemonnier, E., Robin, G., Degrez, C., Tyzio, R., Grandgeorge, M., and Ben-Ari, Y. (2013). Treating Fragile X syndrome with the diuretic bumetanide: a case report. Acta. Paediatrica. 102, e288-e290. doi: 10.1111/apa.12235

Lewis, D. A., Curley, A. A., Glausier, J. R., and Volk, D. W. (2012). Cortical parvalbumin interneurons and cognitive dysfunction in schizophrenia. Trends Neurosci. 35, 57-67. doi: 10.1016/j.tins.2011.10.004

Medina, I., Friedel, P., Rivera, C., Kahle, K. T., Kourdougli, N., Uvarov, P., et al. (2014). Current view on the functional regulation of the neuronal $\mathrm{K}^{+}$$\mathrm{Cl}^{-}$cotransporter KCC2. Front. Cell. Neurosci. 8:27. doi: 10.3389/fncel.2014. 00027

Medrihan, L., Tantalaki, E., Aramuni, G., Sargsyan, V., Dudanova, I., Missler, M., et al. (2008). Early defects of GABAergic synapses in the brain stem of a MeCP2 mouse model of Rett syndrome. J. Neurophysiol. 99, 112-121. doi: 10.1152/jn. 00826.2007

Mefford, H. C., Cooper, G. M., Zerr, T., Smith, J. D., Baker, C., Shafer, N., et al. (2009). A method for rapid, targeted CNV genotyping identifies rare variants associated with neurocognitive disease. Genome. Res. 19, 1579-1585. doi: 10. 1101/gr.094987.109

Mefford, H. C., Sharp, A. J., Baker, C., Itsara, A., Jiang, Z., Buysse, K., et al. (2008). Recurrent rearrangements of chromosome 1q21.1 and variable pediatric phenotypes. N. Engl. J. Med. 359, 1685-1699. doi: 10.1056/nejmoa0805384

Mi, H., Lazareva-Ulitsky, B., Loo, R., Kejariwal, A., Vandergriff, J., Rabkin, S., et al. (2005). The PANTHER database of protein families, subfamilies, functions and pathways. Nucleic. Acids. Res. 33, D284-288. doi: 10.1093/nar/gki078

Mitchell, K. J. (2011). The genetics of neurodevelopmental disease. Curr Opin Neurobiol. 21, 197-203. doi: 10.1002/9781118524947

Neale, B. M., Kou, Y., Liu, L., Ma'ayan, A., Samocha, K. E., Sabo, A., et al. (2012). Patterns and rates of exonic de novo mutations in autism spectrum disorders. Nature. 485, 242-245. doi: 10.1038/nature11011

O'Roak, B. J., Deriziotis, P., Lee, C., Vives, L., Schwartz, J. J., Girirajan, S., et al. (2011). Exome sequencing in sporadic autism spectrum disorders identifies severe de novo mutations. Nat. Genet. 43, 585-589. doi: 10.3410/f.10819956. 11732055

O’Roak, B. J., Vives, L., Girirajan, S., Karakoc, E., Krumm, N., Coe, B. P., et al. (2012). Sporadic autism exomes reveal a highly interconnected protein network of de novo mutations. Nature. 485, 246-250. doi: 10.3410/f.716397823. 791302874

Pescosolido, M. F., Yang, U., Sabbagh, M., and Morrow, E. M. (2012). Lighting a path: genetic studies pinpoint neurodevelopmental mechanisms in autism and related disorders. Dialogues Clin. Neurosci. 14, 239-252.

Purcell, S., Cherny, S. S., and Sham, P. C. (2003). Genetic Power Calculator: design of linkage and association genetic mapping studies of complex traits. Bioinformatics. 19, 149-150. doi: 10.1093/bioinformatics/19.1.149

Purcell, S. M., Moran, J. L., Fromer, M., Ruderfer, D., Solovieff, N., Roussos, P., et al. (2014). A polygenic burden of rare disruptive mutations in schizophrenia. Nature. 506, 185-190. doi: 10.1038/nature12975

Puskarjov, M., Seja, P., Heron, S. E., Williams, T. C., Ahmad, F., Iona, X., et al. (2014). A variant of KCC2 from patients with febrile seizures impairs neuronal Cl- extrusion and dendritic spine formation. EMBO Rep. 15, 723-729. doi: 10. 1002/embr.201438749

Roy, A., Kucukural, A., and Zhang, Y. (2010). I-TASSER: a unified platform for automated protein structure and function prediction. Nat Protoc. 5, 725-738. doi: 10.1038/nprot.2010.5
Rubenstein, J. L. R. (2011). Annual Research Review: Development of the cerebral cortex: implications for neurodevelopmental disorders. J. Child. Psychol. Psychiatry. 52, 339-355. doi: 10.1111/j.1469-7610.2010.02307

Salomons, G. S., Van Dooren, S. J., Verhoeven, N. M., Cecil, K. M., Ball, W. S., Degrauw, T. J., et al. (2001). X-linked creatine-transporter gene (SLC6A8) defect: a new creatine-deficiency syndrome. Am. J. Hum .Genet. 68, 1497-1500. doi: $10.1086 / 320595$

Sanders, S. J., Murtha, M. T., Gupta, A. R., Murdoch, J. D., Raubeson, M. J., Willsey, A. J., et al. (2012). De novo mutations revealed by whole-exome sequencing are strongly associated with autism. Nature. 485, 237-241. doi: 10. 1038/nature10945

Schmidt, M. J., and Mirnics, K. (2014). Neurodevelopment, GABA System Dysfunction and Schizophrenia. Neuropsychopharmacology. 40, 190-206. doi: 10.1038/npp.2014.95

Schwarz, J. M., Rodelsperger, C., Schuelke, M., and Seelow, D. (2010). MutationTaster evaluates disease-causing potential of sequence alterations. Nat. Methods. 7, 575-576. doi: 10.1038/nmeth0810-575

Stefansson, H., Rujescu, D., Cichon, S., Pietilainen, O. P., Ingason, A., Steinberg, S., et al. (2008). Large recurrent microdeletions associated with schizophrenia. Nature. 455, 232-236. doi: 10.1038/nature07229

Talos, D. M., Sun, H., Kosaras, B., Joseph, A., Folkerth, R. D., Poduri, A., et al. (2012). Altered inhibition in tuberous sclerosis and type IIb cortical dysplasia. Ann. Neurol. 71, 539-551. doi: 10.1002/ana.22696

Tanis, J. E., Bellemer, A., Moresco, J. J., Forbush, B., and Koelle, M. R. (2009). The potassium chloride cotransporter KCC-2 coordinates development of inhibitory neurotransmission and synapse structure in Caenorhabditis elegans. J. Neurosci. 29, 9943-9954. doi: 10.1523/jneurosci.1989-09.2009

Tornberg, J., Voikar, V., Savilahti, H., Rauvala, H., and Airaksinen, M. S. (2005). Behavioural phenotypes of hypomorphic KCC2-deficient mice. Eur. J. Neurosci. 21, 1327-1337. doi: 10.1111/j.1460-9568.2005.03959.x

Tuchman, R., and Rapin, I. (2002). Epilepsy in autism. Lancet Neurol. 1, 352-358. doi: 10.1007/978-1-4614-0361-6_24

Tyzio, R., Nardou, R., Ferrari, D. C., Tsintsadze, T., Shahrokhi, A., Eftekhari, S., et al. (2014). Oxytocin-Mediated GABA Inhibition During Delivery Attenuates Autism Pathogenesis in Rodent Offspring. Science. 343, 675-679. doi: 10. $1126 /$ science. 1247190

Ullmann, R., Turner, G., Kirchhoff, M., Chen, W., Tonge, B., Rosenberg, C., et al. (2007). Array CGH identifies reciprocal 16p13.1 duplications and deletions that predispose to autism and/or mental retardation. Hum. Mutat. 28, 674-682. doi: 10.1002/humu.20546

Vissers, L. E., De Ligt, J., Gilissen, C., Janssen, I., Steehouwer, M., De Vries, P., et al. (2010). A de novo paradigm for mental retardation. Nat. Genet. 42, 1109-1112. doi: $10.1038 /$ ng.712

Voineagu, I., Wang, X., Johnston, P., Lowe, J. K., Tian, Y., Horvath, S., et al. (2011). Transcriptomic analysis of autistic brain reveals convergent molecular pathology. Nature. 474, 380-384. doi: 10.1038/nature10110

Woo, N. S., Lu, J., England, R., Mcclellan, R., Dufour, S., Mount, D. B., et al. (2002). Hyperexcitability and epilepsy associated with disruption of the mouse neuronal-specific K-Cl cotransporter gene. Hippocampus. 12, 258-268. doi: 10. 1002/hipo.10014

Xu, B., Roos, J. L., Dexheimer, P., Boone, B., Plummer, B., Levy, S., et al. (2011). Exome sequencing supports a de novo mutational paradigm for schizophrenia. Nat. Genet. 43, 864-868. doi: 10.1038/ng.902

Zhu, L., Polley, N., Mathews, G. C., and Delpire, E. (2008). NKCC1 and KCC2 prevent hyperexcitability in the mouse hippocampus. Epilepsy Res. 79, 201-212. doi: 10.1016/j.eplepsyres.2008.02.005

Conflict of Interest Statement: The authors declare that the research was conducted in the absence of any commercial or financial relationships that could be construed as a potential conflict of interest.

Copyright $\odot 2015$ Merner, Chandler, Bourassa, Liang, Khanna, Dion, Rouleau and Kahle. This is an open-access article distributed under the terms of the Creative Commons Attribution License (CC BY). The use, distribution and reproduction in other forums is permitted, provided the original author(s) or licensor are credited and that the original publication in this journal is cited, in accordance with accepted academic practice. No use, distribution or reproduction is permitted which does not comply with these terms. 